\title{
Comparative genomics of unintrogressed Campylobacter coli clades 2 and 3
}

\author{
Caroline PA Skarp-de Haan ${ }^{1 *}$, Alejandra Culebro ${ }^{1}$, Thomas Schott', Joana Revez ${ }^{1}$, Elke KH Schweda², \\ Marja-Liisa Hänninen ${ }^{1}$ and Mirko Rossi ${ }^{1}$
}

\begin{abstract}
Background: Campylobacter jejuni and C. coli share a multitude of risk factors associated with human gastrointestinal disease, yet their phylogeny differs significantly. C. jejuni is scattered into several lineages, with no apparent linkage, whereas C. coli clusters into three distinct phylogenetic groups (clades) of which clade 1 has shown extensive genome-wide introgression with C. jejuni, yet the other two clades (2 and 3) have less than 2\% of C. jejuni ancestry. We characterized a C. coli strain (76339) with four novel multilocus sequence type alleles (ST-5088) and having the capability to express gamma-glutamyltranspeptidase (GGT); an accessory feature in C. jejuni. Our aim was to further characterize unintrogressed C. coli clades 2 and 3, using comparative genomics and with additional genome sequences available, to investigate the impact of horizontal gene transfer in shaping the accessory and core gene pools in unintrogressed C. coli.

Results: Here, we present the first fully closed C. coli clade 3 genome (76339). The phylogenomic analysis of strain 76339, revealed that it belonged to clade 3 of unintrogressed C. coli. A more extensive respiratory metabolism among unintrogressed C. coli strains was found compared to introgressed C. coli (clade 1). We also identified other genes, such as serine proteases and an active sialyltransferase in the lipooligosaccharide locus, not present in C. coli clade 1 and we further propose a unique scenario for the evolution of Campylobacter ggt.

Conclusions: We propose new insights into the evolution of the accessory genome of C. coli clade 3 and C. jejuni. Also, in silico analysis of the gene content revealed that C. coli clades 2 and 3 have genes associated with infection, suggesting they are a potent human pathogen, and may currently be underreported in human infections due to niche separation.
\end{abstract}

Keywords: Campylobacter coli, Comparative genomics, Phylogeny, Gamma glutamyltranspeptidase, Sialyltransferase

\section{Background}

Campylobacter jejuni and C. coli are the most common bacterial cause for gastroenteritis in industrialized countries [1] and have been implicated in the development of several post-infectious sequelae [2,3]. Most research has focused on C. jejuni, but the role of C. coli in human disease is being increasingly recognized [4-7]. Both species share common risk factors for human infections, such as consumption of poultry, foreign travel, and drinking untreated water [6,8-10]. However, several case-case studies have also observed differences in the risk factors associated with either species, such as C. coli being

\footnotetext{
* Correspondence: astrid.dehaan@helsinki.fi

${ }^{1}$ Department of Food Hygiene and Environmental Health, Helsinki University, Helsinki, Finland

Full list of author information is available at the end of the article
}

more common in the elderly and those living in rural areas $[4,7,9,11]$. In addition, $C$. jejuni is most commonly found in poultry and ruminants, whereas $C$. coli colonizes pigs more frequently. Nevertheless, C. coli is also found in poultry, and it has been suggested that the populations circulating in these animal species are different [12].

Phylogenetic analyses by Sheppard et al. [13,14] have shown that $C$. coli strains cluster into three distinct phylogenetic groups (clades). In their analyses, both C. coli multilocus sequence type (MLST) ST-828 and ST-1150 clonal complexes were found in a clade (designated as introgressed clade 1) which showed extensive genomewide introgression with $C$. jejuni $[13,14]$. On the contrary, many uncommon C. coli STs, not assigned to a clonal complex, clustered into two separate clades (unintrogressed clades 2 and 3) and showed less than $2 \%$ of $C$. jejuni

\section{Biomed Central}


ancestry, indicating that cross-species exchange had little or no impact on the gene pools of these lineages [14].

Although the ST-828 clonal complex accounts for the majority of $C$. coli infections in Finland, we recently identified a C. coli isolate (76339) from a patient with a domestically acquired infection which had a novel multilocus sequence type (ST-5088) and was deposited into the PubMLST database (http://pubmlst.org/campylobacter/) [15]. Further characterization of this strain showed that it produced gamma-glutamyltranspeptidase (GGT), which belongs to the accessory genome of $C$. jejuni. GGT is widely distributed in living organisms and is highly conserved. It belongs to the core genome of all gastric Helicobacter species and some enterohepatic Helicobacter spp. [16]. However, among Campylobacter spp. it has been detected in only a subset of $C$. jejuni strains [17], and has shown a strong association with only certain C. jejuni STs $[18,19]$. The presence of GGT in $C$. coli has not been described before and opens a question concerning the real impact of cross-species gene exchange between $C$. jejuni and unintrogressed C. coli lineages.

To investigate the impact of horizontal gene transfer in shaping accessory and core gene pools in unintrogressed C. coli, we carried out an extensive genomic characterization of $C$. coli, with special emphasis on C. coli clades 2 and 3 . We provide the first closed genome of a C. coli belonging to clade 3 (strain 76339) on which we have performed an in-depth analysis of the gene content and phylogeny. We further defined the core and pan genome of unintrogressed C. coli clades 2 and $3[13,14]$ and propose a novel view on the evolution of these lineages and their accessory gene content. Finally, we show evidence for a sialylated lipooligosaccharide (LOS) locus structure; a novel feature for unintrogressed C. coli clade 3.

\section{Methods}

Bacterial strain 76339, DNA extraction and MLST

C. coli strain 76339 was isolated from a human patient with a domestically acquired infection in July 2006 [20]. The species was confirmed using species-specific PCR [21] and frozen at $-70^{\circ} \mathrm{C}$ in skim milk with $20 \%$ glycerol. Subsequent cultivations were routinely done on Nutrient Agar (Oxoid, Basingstoke, England) supplemented with $5 \%$ horse/bovine blood.

DNA was isolated with the Wizard Genomic DNA Purification Kit (Promega, Mannheim, Germany). MLST was performed as described previously [22-25].

\section{Whole genome sequences and annotation}

The genome of C. coli 76339 was obtained using 454 Titanium (Roche; performed by LGC Genomics GmbH, Berlin, Germany) with a $>30 \times$ fold coverage. A combination of a pair-end and $8 \mathrm{~kb}$ mate-pair libraries was assembled into a scaffold representing a circular chromosome using MIRA 3.2. [26], SSAKE [27], and the Staden software package [28]. Verification of the scaffold was performed using PCR and Sanger sequencing. The shot-gun sequences of 63 other $C$. coli strains (Additional file 1: Table S1) were either downloaded from the NCBI ftp server or kindly provided by Dr. Samuel Sheppard (College of Medicine, Swansea University). Of these $63 \mathrm{C}$. coli strains, 54 were belonging to clade 1 , four to clade 2 and five to clade 3 . For gene finding and automatic annotation, the complete genome sequence of C. coli 76339 and all the other C. coli shot-gun sequences were uploaded to the RAST server [29]. The coding sequence of $C$. coli 76339 was further analysed using the Artemis tool [30] and manually re-annotated the genes of special interest. In particular, homology was identified using NCBI's BLAST suite of programs with UniProtKB/ Swiss-Prot as reference database and the conserved functional domains in proteins were identified using InterProScan [31]. For the prediction of glycosyltransferases we referred to the annotation available in the CAZy database [32]. The genomes of C. coli and C. jejuni used in this study are listed in Additional file 1: Table S1.

\section{Phylogenetic analysis}

For the phylogenomics of C. coli and C. jejuni, the downloaded genomes were aligned with the multiple whole genome alignment tool Mugsy [33] by using the "-distance 1000" and "-minlength 100" options, as previously described [34]. The MAF blocks were concatenated and transformed in FASTA file format using the script available in Galaxy [35-37]. The resulting core alignment was filtered using Gblocks [38] with the minimum length of a block set at $100(\mathrm{~b} 4=100)$. A maximum likelihood tree was built using FastTree 2, applying the generalized timereversible model (GTR) [39,40]. The model of evolution was selected using jmodeltest 2 [41]. In order to reconstruct the species tree of C. coli, a second analysis was performed. A fraction of the core genomes (calculated with OrthoMCL, see below) of C. coli strains 317_04, RM2882, BIGS10 and 76339 (each representing one of the four major monophyletic phylogenetic groups) which showed orthologs in the outgroup species C. upsaliensis was selected. Alignments for each of the one-to-one rooted core genes (543 orthologs) were first generated at the amino acid level using MAFFT-FFT-NS-i v.7 [42], then backtranslated to nucleotide sequence using Translatorx perl script [43]. To account for the presence of possible recombination between the strains, each gene alignment was analysed using 3Seq in fullrun mode, setting the Bonferroni-corrected P-value cut-off at $0.05[44,45]$, and using Pairwise Homoplasy Index [46], Maximum $\chi^{2}$ [47] and the Neighbour Similarity Score [48], all implemented in PhiPack package [49]. The programme PhiPack was 
run by setting window size at 5 and the p-value of observing the sequences under the null hypothesis of no recombination at 0.05 . To assess significance, 100 permutations tests were performed. Genes identified as unrecombined by all the four methods were selected for further analysis. The phylogenetic trees of each aligned unrecombined gene and of the concatenated alignments were inferred using PhyML [50] by applying the following parameters: -b -2, -m GTR, -o tlr, -a e, -c 6. A consensus tree based on the 543 maximum likelihood trees was generated using the extended Majority Rule method implemented in CONSENSE program available in PHYLIP package [51].

The phylogenetic trees of gamma-glutamyl transpeptidases (GGTs), sialyltransferases (Cst) and 16S rRNA genes were reconstructed using Bayesian phylogenetic inference. Homologs of GGT and Cst sequences were available from previous studies $[16,52]$. The nucleotide sequences were aligned based on amino acid alignment using PRANK by applying the TranslatorX perl script [43]. A multisequence alignment of full-length 16S rRNA genes of the type bacterial strains belonging to $\varepsilon$ proteobacteria was downloaded from the RDP website [53]. Two independent analyses of four MCMC chains run for 10 million generations with a tree sample each 10,000 generations were conducted for each gene using MrBayes v 3.2.1 [54]. GTR (nucmodel $=4$ by 4 nst $=6$ ) was selected as evolutionary model and the number of discrete categories used to approximate the gamma distribution was set to $6($ rates = gamma ngammacat $=6)$. To determine whether the data sets support conflicting phylogenies or a single tree, Neighbor-net networks were generated using Splitstree 4 [55].

\section{Comparative genomics}

Orthologous and paralogous groups were determined using OrthoMCL version 2.0.2 [56]. A database of 111,061 amino acid sequences, including all the translated coding sequences (tCDSs) of annotated 64 C. coli genomes, was assembled (Ccoli-DB). Reciprocal all-versus-all BLASTP was performed and the results were processed by OrthoMCL using default parameters (thresholds to blast result: E-value $<1 \mathrm{e}-5$, percent match length $\geq 50 \%$ ) [56]. The OrthoMCL output was filtered to produce different lists of ortholog/paralog groups which contained: (i) tCDSs from all C. coli strains (core genome); (ii) tCDS from all the genomes of a clade; (iii) tCDSs from all the genomes of a clade and missing in the other clades; (iv) tCDSs from at least one genome of a clade and missing in the other clades.

To identify common orthologs between C. coli 76339 and the other 63 C. coli strains (Additional file 1: Table S1), a second approach was used. The complete set of predicted proteins of C. coli 76339 was compared to the panproteome including C. coli strains belonging to clade 1 , clade 2 or clade 3, by reciprocal BLASTP using BLAST score ratio (BSR). The BSR was computed as previously described [57]. For each dataset, the BLAST raw score for each $C$. coli tCDS against itself was stored as the Reference score. Each $C$. coli tCDS was then compared to each tCDS of the C. coli 76339 predicted proteome with each best BLAST raw score recorded as Query score. The BSR is calculated by dividing the Query score by the Reference score for each tCDS. A cut-off of 0.4 was used to define if two tCDSs were homologs. This approach is more stringent than OrthoMCL and able to separate distant proteins which may be clustered in the same group by MCL.

\section{Phenotypic analysis}

GGT activity was measured qualitatively as described before [58]. The LPS was extracted from C. coli 76339 grown in Nutrient Broth for 24 hours using the hot phenol-water method, and subjected to high performance anion-exchange chromatography with pulsed amperometric detection (HPAEC-PAD) for the detection of sialic acid, as previously described [52].

\section{Results and discussion}

\section{General features of $C$. coli 76339 and definition of the} core genome

A summary of the features of C. coli 76339 is given in Table 1 and a circular plot of the chromosome is presented in Figure 1. The genome of C. coli 76339 consists of a single chromosome which includes 1,556 proteincoding sequences (CDSs) in a coding area of $93.4 \%$. A putative function could be predicted for 1,412 (90.7\%) of the CDSs, whereas 144 (9.2\%) of the CDSs were annotated as hypothetical proteins. Plasmids, insertion sequences (IS), prophages, and genomic islands were not detected in C. coli 76339, differentiating this strain from C. coli RM2228 [59]. Compared to other published $C$. coli and C. jejuni genomes, 76339 strain has a smaller chromosome and, consequently, possesses a lower number of CDSs $[59,60]$.

Based on MCL clustering, 97\% of 111,061 the C. coli translated CDSs (tCDSs) included in the analysis could be divided into 2,951 groups of orthologs (GOs). A total of 1,524 GOs were detected in the proteome of C. coli 76339 comprising $98.8 \%$ of the complete set of tCDSs. Only 18 tCDSs did not belong to any GOs, and were unique for C. coli 76339 (Table 2). The core genome of C. coli, defined as the list of orthologs present in all $C$. coli strains, consisted of 654 GOs. This value was lower than that found with a previous OrthoMCL analysis performed with $42 \mathrm{C}$. coli strains [60]. In the study of Lefébure et al. [60], the core genome of C. coli was defined differently allowing a single strain to miss a core gene, and the authors estimated the core genome to include 1,485 GOs. However, even with a more relaxed definition, allowing a 
Table 1 Features of the Campylobacter coli 76339 genome

\begin{tabular}{|c|c|c|}
\hline \multirow[t]{2}{*}{ Feature } & \multicolumn{2}{|c|}{ Strain } \\
\hline & 76339 & $\mathrm{RM} 2228$ \\
\hline Origin & Clinical (stool) & Chicken \\
\hline Multilocus sequence type & ST-5088 & ST-1063 \\
\hline Clonal complex & - & 828 \\
\hline Allelic profile (aspA:gInA:gltA:glyA:pgm:tkt:uncA) & $121: 278: 328: 431: 552: 452: 154$ & 33:39:30:140:113:43:4 \\
\hline C. coli clade & 3 & $1 b$ \\
\hline Chromosome size & $1,584,486 \mathrm{bp}$ & $\sim 1.68 \mathrm{Mb}$ \\
\hline GC content & $32.26 \%$ & $31.37 \%$ \\
\hline Coding sequences (CDS) & 1556 & 1764 \\
\hline Assigned function & 1412 & 1304 \\
\hline Hypothetical proteins & 144 & 336 \\
\hline \multicolumn{3}{|l|}{ Restriction/Modification systems } \\
\hline Type I & 2 & 1 \\
\hline Type ॥ & 1 & 2 \\
\hline CRISPR & Yes & No \\
\hline
\end{tabular}

single strain to miss multiple core genes, we estimated the core genome of $C$. coli to have only 891 GOs. Our estimation is quite similar to the size of the core genome of the genus Campylobacter which comprises 647 OrthoMCL GOs [61].

\section{Phylogenomics of C. coli 76339 and delineation of $C$. coli species tree}

The phylogenetic position of $C$. coli 76339 is shown in Figure 2. The whole-genome alignment of 4,772,631 bp, including 64C. coli genomes and five C. jejuni strains (Additional file 1: Table S1), were treated with Gblocks which resulted in a gap-less multi-sequence alignment of 347,477 bp $(\sim 7 \%$ of the original multi-sequence alignment), which was used to build a Maximum Likelihood (ML) tree. The topology of the ML tree, based on the whole-genome alignment, resembled the neighbourjoining tree based on average genetic distances previously published by Sheppard et al. [14], and placed C. coli 76339 in clade 3 of unintrogressed strains [14]. In both the ML and the NJ tree, the branch of $C$. jejuni intersects the $C$. coli tree between clade 1a (ST-828 CC) and $1 \mathrm{~b}$ (ST-1150 CC). As previously described, this position does not reflect the true evolution of $C$. coli, but instead is a consequence of introgression (interspecies recombination) of clade 1 , and in particular of $C$. coli CC 1150, with C. jejuni [14]. This result indicates that interspecies recombination influences the topology of a ML tree when based on whole-genome alignment.

A previous study showed that in a tree based on 35 ribosomal proteins with no evidence of homologous recombination, the branch containing $C$. jejuni intersected the
C. coli tree near to clade 3 [14]. Rooting this tree using $C$. jejuni as an outgroup showed that clade 3 has evolved from a common ancestor before the separation of clade 1 and 2 [Figure 3A and B, ref. [14], indicating that the unintrogressed $C$. coli strains are paraphyletic. In order to verify the evolution of $C$. coli, we inferred the species tree using a different approach. We selected one genome for each $C$. coli clade and $C$. upsaliensis, which has been demonstrated to be a sister group to the $C$. jejuni/C. coli clade [61], was chosen as an outgroup. We selected a total of 228 core genes out of 543 showing no statistically significant recombination among the strains. The ML tree obtained after concatenating those 228 unrecombined core genes showed that $C$. upsaliensis intersects the $C$. coli tree between clade 1 , and clades 2 and 3 (Figure 3C). Both nodes are well supported with $\chi^{2}$-based parametric branch values of $>99 \%$. In addition, the same topology was inferred by estimating the consensus tree of each of the 228 single gene trees using the extended majority rule method (data not shown), supporting the results obtained with concatenated genes. In fact, the splits 'cladela, clade1b | C. upsaliensis, clade 2, clade 3' and 'clade1a, clade1b, C. upsaliensis | clade 2, clade 3' were present in $60.9 \%$ and $43.4 \%$ of the gene trees, respectively. In contrast, the split 'clade 2, clade1a, clade1b | C. upsaliensis, clade 3', which would support the topology of the concatenated unrecombined rps genes proposed by Sheppard et al. [14], was present in only $28 \%$ of the gene trees.

In summary, our data analysis showed that the unintrogressed C. coli strains are monophyletic (Figure 3C), suggesting a different evolutionary history than proposed by Sheppard et al. [14]. 


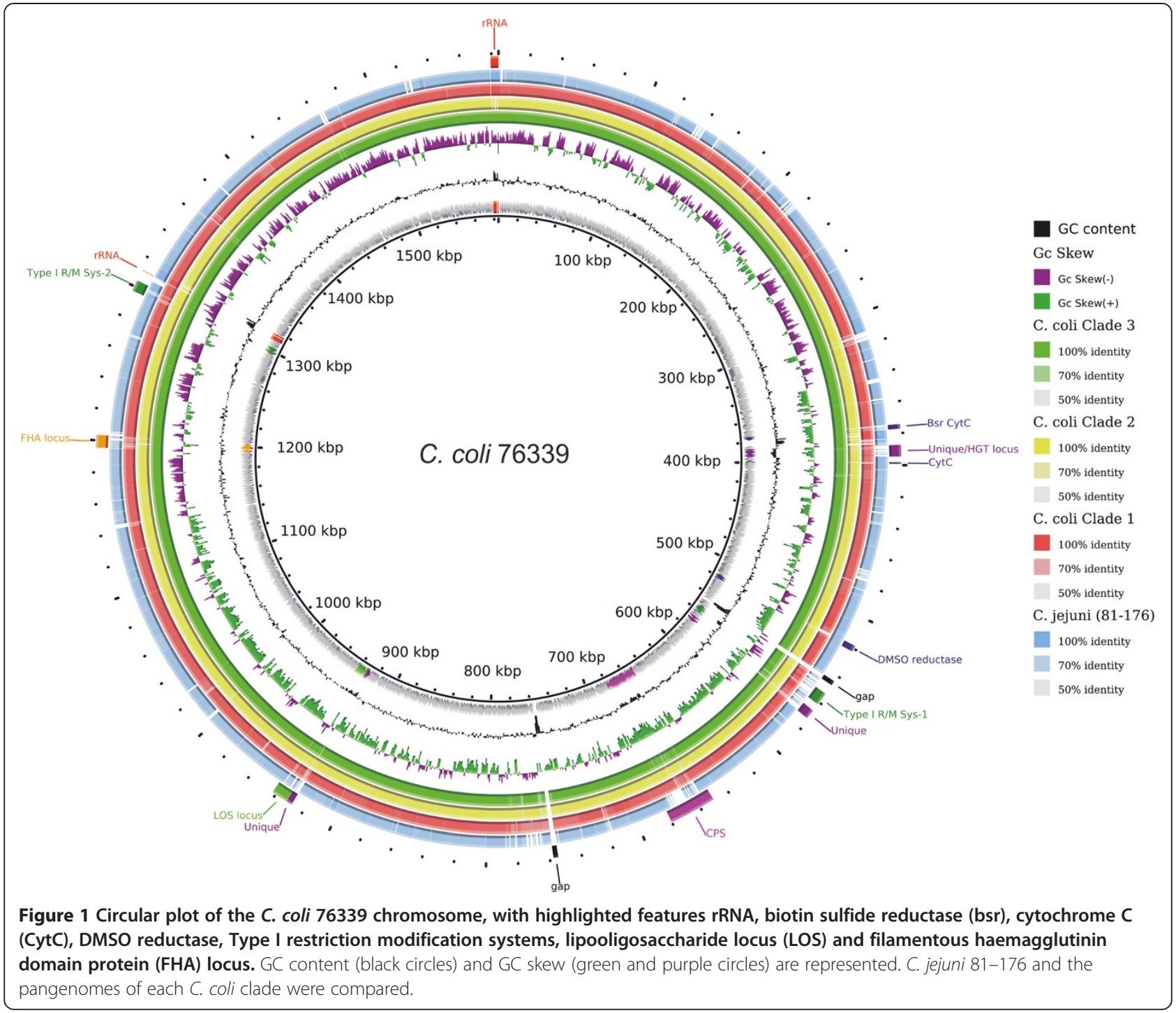

\section{Unique features of $C$. coli clade 3}

A total of 1,282 GOs ( $84 \%$ of the GOs detected in C. coli 76339) were detected in all the studied strains belonging to clade 3. However, only six GOs were unique to this clade: a putative protease (GO-CCO3301; BN865_02000), a protein belonging to Cytochrome-c family (GO-CCO3300; BN8 65_04240) and a second DMSO reductase system (includes four GOs: chain A GO-CCO3235, BN865_05620; chain B GO-CCO3303, BN865_05610; chain C, GO-CCO3302, BN 865_05600; chain D GO-CCO3392, BN865_05590 which was missing in one strain of clade 3 ).

\section{Serine proteases}

The first GO unique to $C$ coli clade 3 strains includes a protease (BN865_02000) which was found to contain an immunoglobulin A1 protease domain in the $\mathrm{N}$-terminus and an autotransporter in the C-terminus. In three strains of clade 3 , the protein is probably fragmented and homology was found only in the C-terminal part. This protein belongs to the MEROPS peptidase family S6 and bears significant homology to members of the autotransporter family, such as the serine protease autotransporters of Enterobacteriacae (SPATE) [62]. It had significant BLASTP hits with putative uncharacterized serine proteases of $C$. jejuni (e.g. $47 \%$ amino acid identity with CJM1_0203 of C. jejuni M1). However, the homology is limited to the $\mathrm{N}$-terminus of the sequence and does not include the autotransporter domain. Reciprocal BLASTP allowed the identification of another serine protease autotransporter in C. coli 76339 (BN865_07680) which gave a significant BSR ( $>0.4$ ) with sequences of only clade 3 strains. These sequences belong to the GO-CCO3075, which also contains four proteins present in C. coli clade 1 strains. These proteins share the same domains and belong to the MEROPS peptidase family S8A, which includes homologs to subtilisin [62]. The clade 3 subtilisin- 
Table 2 Unique CDSs of C. coli 76339

\begin{tabular}{|c|c|}
\hline Locus tag & RAST annotation \\
\hline BN865_00400c & GTP-binding protein EngA \\
\hline BN865_01640 & $\begin{array}{c}\text { Methyl-accepting chemotaxis signal transduction } \\
\text { protein }\end{array}$ \\
\hline BN865_01690 & Diacylglycerol kinase (EC 2.7.1.107) \\
\hline BN865_01750 & Highly acidic protein \\
\hline BN865_02020c & $\begin{array}{c}\text { DNA modification methylase (Adenine-specific } \\
\text { methyltransferase) (EC 2.1.1.72) }\end{array}$ \\
\hline BN865_03900 & Putative periplasmic protein \\
\hline BN865_04140 & Hypothetical protein \\
\hline BN865_04150 & Hypothetical protein \\
\hline BN865_04190 & Hypothetical protein \\
\hline BN865_06070 & Filamentous haemagglutinin domain protein \\
\hline BN865_09290 & Membrane protein \\
\hline BN865_09810c & Hypothetical protein \\
\hline BN865_09820c & $\begin{array}{l}\text { Probable poly(beta-D-mannuronate) } \\
\text { O-acetylase (EC 2.3.1.-) }\end{array}$ \\
\hline BN865_10710 & Small hydrophobic protein \\
\hline BN865_11290 & Putative mechanosensitive ion channel \\
\hline BN865_12980C & Predicted permease YjgP/YjgQ family \\
\hline BN865_13630c & ABC transporter, ATP-binding protein-related protein \\
\hline BN865_13830 & Putative integral membrane zinc-metalloprotease \\
\hline
\end{tabular}

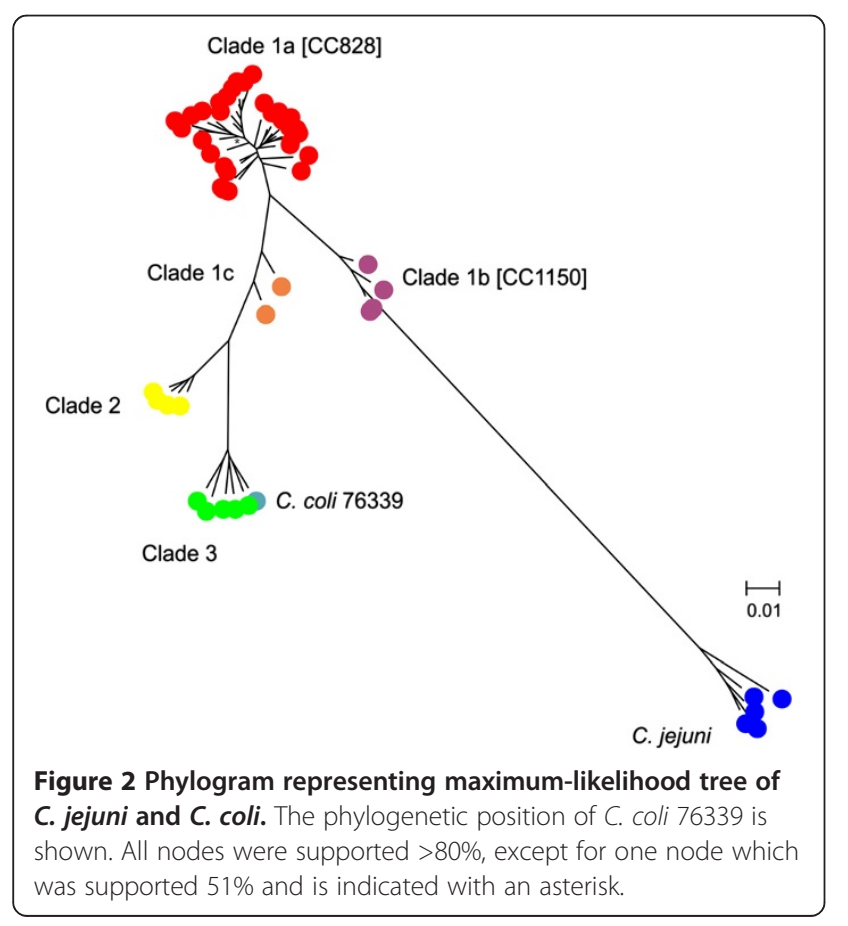

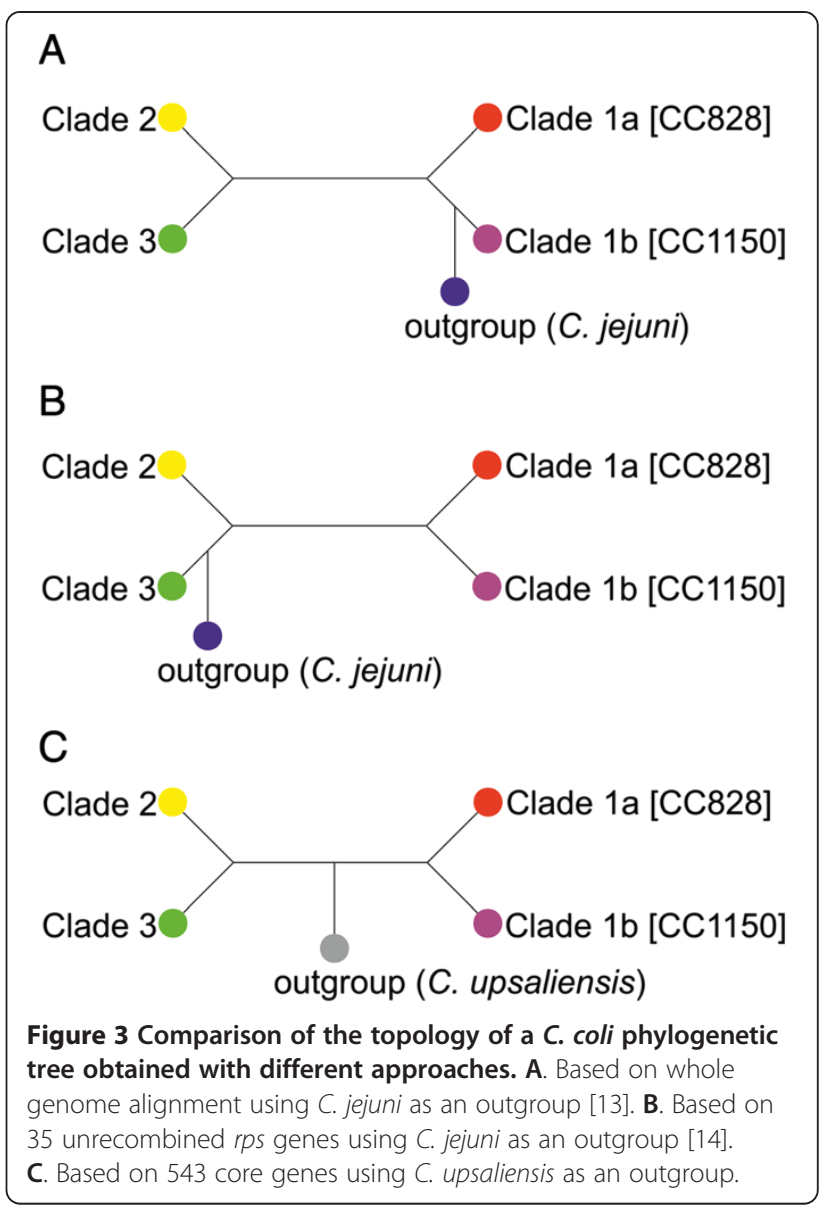

like proteins were distantly related to homologs of $C$. upsaliensis (55\% identity) and C. jejuni 81-176 (53\% identity with CJJ81176_1371). In contrast, the clade 1 subtilisin-like protein was $100 \%$ identical to the C. jejuni 81-176 serine protease CJJ81176_1367. This indicates that the evolutionary dynamics of both clade 3 serine proteases is difficult to predict. The monophyletic relationship between clade 2 and 3 (Figure 3C) suggests gene extinction would not be parsimonious and thus horizontal gene transfer (HGT) could have played a major role. Nevertheless, gene extinction cannot be completely excluded and would be well supported by the topology of the species tree proposed by Sheppard et al. [14] in which clades 2 and 3 are paraphyletic.

\section{Cytochrome-c family protein and a second DMSO reductase system}

Additional features that characterized C. coli clade 3 were the Cytochrome-c (CytC) family protein and a second DMSO reductase system. Both are likely involved in the respiratory chain, and may confer a metabolic advantage to these strains. Both systems have homologs in C. jejuni; CytC BN865_04240 showed 91\% nucleotide identity with Cj0037 of C. jejuni NCTC 11168 and may 
have been exchanged between $C$. jejuni and C. coli clade 3. The second DMSO system is organized as described in C. jejuni 81-176 [63] and is located in the same region of the genome, yet it's lower amino acid identity with C. jejuni $81-176$ ( $80 \%$ amino acid identity between BN865_05620 and CJJ81176_1570) suggests an origin different from CytC.

As observed for the serine proteases, a scenario of gene extinction would be supported by the topology of the species tree proposed by Sheppard et al. [14]. The monophyletic relationships between clade 2 and 3 that we found, however, suggests that $C$. coli clade 3 and certain lineages of $C$. jejuni might have acquired the second DMSO system by HGT from independent sources. This makes it tempting to speculate that during the evolution of $C$. coli clade 3 the second DMSO system might have been acquired as a consequence of niche adaptation.

\section{Additional features of $C$. coli clade 3}

In addition to the six specific $C$. coli clade 3 GOs, a total of 18 extra GOs were found to be present in at least one genome of clade 3 , but missing in the other C. coli genomes (Table 3). Several of these groups contain small putative proteins with unknown function, and only a few were also detected in C. coli 76339: a hypothetical protein containing a $\mathrm{C}$-terminal autotransporter domain (BN865_03550); a hemerythrin family non-heme iron protein (BN865_01820) and two other hypothetical proteins (BN865_05590; BN865_10320).

\section{TonB2 and GGT are two common features characterizing} unintrogressed clade 2 and $3 \mathrm{C}$. coli strains

A total of 25 GOs were detected to be common in $C$. coli strains belonging to clades 2 and 3 (present in at least one strain of both clades), but missing in clade 1 (Table 4). Among these, a gene homologous to C. jejuni tonB2 (GO-CCO3049; BN865_05130) was found to be common in all the strains belonging to clades 2 and 3 . In addition to ton $B 2$, the gene encoding gamma glutamyltranspeptidase; ggt (GO-CCO3111; BN865_04090) was common in all but one unintrogressed $C$. coli strains.

\section{TonB2 transport protein}

The TonB protein is involved in iron acquisition and exists in a complex with ExbB and ExbD, which provides the energy for transport of ferric $\left(\mathrm{Fe}^{3+}\right)$ iron through the outer membrane receptors [64-66]. So far, a total of three $\operatorname{ton} B$ homologs have been described in $C$. jejuni and the majority of $C$. jejuni strains contain all genes, yet some strains (e.g. C. jejuni 81-176 and 81116) possess only tonB2 [67]. Similar to C. jejuni, tonB1 and ton $B 3$ belong to the core genome of $C$. coli and due to the surplus of sequenced $C$. coli clade 1 strains, the presence of a third tonB gene in C. coli was unknown. Here,

Table 3 Group of orthologs (GO) unique to C. coli clade 3

\begin{tabular}{|c|c|c|}
\hline Group of orthologs (GOs) & RAST annotation & Locus tag 76339 \\
\hline CCO3388 & Nitroreductase family protein & \\
\hline CCO3390 & Hypothetical protein & \\
\hline CCO3392 & Hypothetical protein CJJ81176_1573 & BN865_05590c \\
\hline CCO3393 & Hemerythrin family non-heme iron protein & BN865_01820 \\
\hline CCO3489 & Hypothetical protein (autotransporter) & BN865_03550 \\
\hline CCO3490 & Small putative protein & BN865_10320 \\
\hline CCO3520 & NADPH:quinone reductase and related Zn-dependent oxidoreductases & \\
\hline CCO3645 & Small putative protein & \\
\hline CCO3646 & Major antigenic peptide PEB3 & \\
\hline CCO3648 & Small putative protein & \\
\hline CCO3649 & Small putative protein & \\
\hline CCO3793 & Small putative protein & \\
\hline CCO3794 & Small putative protein & \\
\hline CCO3799 & Small putative protein & \\
\hline CCO3800 & Methyltransferase & \\
\hline CCO3801 & Small putative proteln & \\
\hline CCO3802 & Small putative protein & \\
\hline CCO3880 & Small putative protein & \\
\hline
\end{tabular}

The GOs describe here were present in at least one genome of $C$. coli clade 3, but missing in all other $C$. coli strains. 
Table 4 Group of orthologs unique to $C$. coli clades 2 and 3

\begin{tabular}{|c|c|c|}
\hline $\begin{array}{l}\text { Group of } \\
\text { orthologs (GOs) }\end{array}$ & RAST annotation & $\begin{array}{l}\text { Locus tag } \\
76339\end{array}$ \\
\hline CCO3049 & tonB2 & BN865_05130 \\
\hline CCO3111 & GGT & BN865_04090c \\
\hline CCO3112 & Small putative protein & \\
\hline cCO3236 & Small putative protein & BN865_04140 \\
\hline CCO3255 & Type I R/M system & BN865_13650c \\
\hline CCO3348 & Small putative protein & \\
\hline CCO3368 & Small putative protein & \\
\hline CCO3391 & Type I R/M system & BN865_13620C \\
\hline CCO3394 & Chloramphenicol acetyltransferase & BN865_06010 \\
\hline CCO3395 & Hypothetical protein & BN865_11580 \\
\hline CCO3433 & DnaJ superfamily & \\
\hline CCO3436 & Small putative protein & \\
\hline CCO3459 & $\begin{array}{l}\text { Hypothetical protein - Helicobacter } \\
\text { homolog }\end{array}$ & BN865_10830 \\
\hline CCO3522 & Small putative protein & \\
\hline CCO3574 & Aldo/keto reductase family & \\
\hline CCO3575 & Putative transcriptional regulator & \\
\hline CCO3577 & Small putative protein & \\
\hline CCO3674 & Type I R/M system & BN865_13640c \\
\hline CCO3724 & Aldo/keto reductase family & \\
\hline CCO3726 & Small putative protein & \\
\hline CCO3737 & Small putative protein & \\
\hline CCO3896 & Recombination protein $\mathrm{T}$ & \\
\hline CCO3899 & Small putative protein & \\
\hline CCO3945 & Small putative protein & \\
\hline CCO3946 & Small putative protein & \\
\hline
\end{tabular}

The GOs described here were present in at least one genome of $C$. coli clade 3 and 2 , but missing in C. coli clade 1 .

we show, for the first time, the presence of tonB2 in C. coli, which is limited to clade 2 and 3 strains.

\section{Gamma glutamyltranspeptidase}

Similar to C. jejuni, the ggt gene in C. coli 76339 is located downstream of a ribosomal operon, which is considered to be a recombinational hotspot and together with the accessory nature of C. jejuni ggt [17], this suggests that the $C$. coli ggt could have been acquired by HGT [68]. In order to investigate the possible origin of ggt in Campylobacter spp., the phylogeny of ggt orthologs in $\varepsilon$-proteobacteria was reconstructed using Bayesian inference (Figure 4A) and compared to a Bayesian species tree of the $\varepsilon$-proteobacteria based on the small ribosomal unit (Additional file 2: Figure S1). Both tree topologies support the hypothesis that ggt was acquired by an ancestral Campylobacter species through HGT and originated from an ancestral Helicobacter species. However, after acquisition and during evolution of both C. jejuni and C. coli, the gene underwent progressive extinction. This hypothesis is supported by several lines of evidence. First, the presence of ggt in only unintrogressed $C$. coli isolates suggests that the gene evolved separately after speciation and was not exchanged between the two species. This is corroborated by a split decomposition analysis which showed no net-like structure between C. coli and C. jejuni ggt (Figure 4b). Furthermore, the gene extinction scenario is also supported by the topology of both proposed C. coli species trees (Sheppard et al. [14] and this study). Progressive extinction could also be inferred for $C$. jejuni. The rooted ML tree, representing the evolution of $C$. jejuni (Additional file 3: Figure S2), shows that ggt gradually disappears while moving away from the root. In C. jejuni, ggt is typically found in multilocus sequence types (STs) that are predominant in chickens opposed to those STs that are predominant in bovines and barnacle geese [18]. Therefore, the original advantage associated with the acquisition of $g g t$ may have vanished during the adaptation of C. coli and C. jejuni as a consequence of niche segregation [69].

\section{Additional features of unintrogressed $C$. coli strains}

C. coli 76339 possesses, in common with three other clade 3 strains and one clade 2 strain, a gene containing a chloramphenicol acetyltransferase domain (GO-CCO3394; BN 865_06010) which is located immediately downstream of a highly conserved alcohol dehydrogenase (GO-CCO1275; BN865_06000). Although C. coli 76639 expressed BN86 5_06010 in vitro, the MIC for chloramphenicol was lower than $1 \mathrm{mg} / \mathrm{L}$ (data not shown), indicating that the gene may not be able to confer resistance to chloramphenicol and is probably misannotated.

Another interesting feature is the structure known as clustered regularly interspaced short palindromic repeat (CRISPR) locus, which is considered to function as a prokaryotic immune system and protects against invasion of alien genetic elements, e.g. plasmids and phages [70]. The CRISPR locus of $C$. coli clades 2 and 3 consists of four spacers and a putative trans-encoded sRNA sequence (based on nucleotide similarity with $C$. jejuni 81116 tracrRNA [71]). The CRISPR/cas system in C. coli 76339 and other clade 3 strains possess only the cas 9 gene (GO CCO2663; BN865_15240c), but homologs for cas 1 and cas 2 are absent. Homologs of the C. jejuni CRISPR/cas system were found in all strains belonging to clade 2 and a subset of clade 1 strains. However, the location of the CRISPR/cas system in the genomes distinguishes introgressed clade 1 from unintrogressed C. coli clades 2 and 3 . In unintrogressed C. coli clades 2 and 3 the CRISPR locus is found between $\operatorname{rodA}$ and $d n a B$, whereas in the strains of clade 1 the locus is 


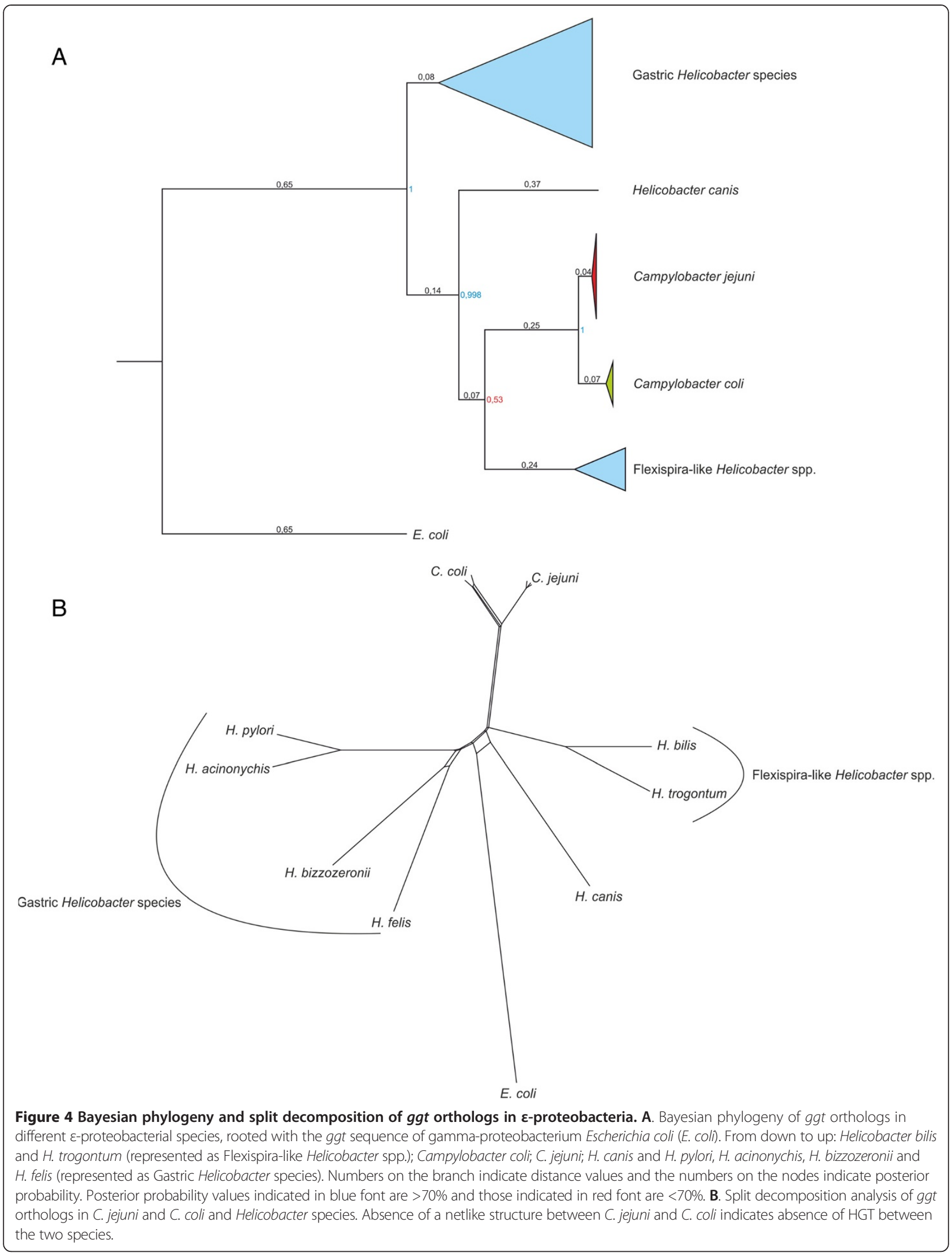


located in the same position of the genome as described for C. jejuni (between moeA2 and purM [71]). These data corroborate the hypothesis of interspecies recombination between $C$. coli clade 1 and $C$. jejuni proposed by Sheppard et al. [14] as well as the monophyletic relationship between C. coli clade 2 and 3 .

\section{Gene flow between $C$. coli clades}

Sheppard et al. [14] estimated a $4 \%$ genetic exchange between the three C. coli clades. We found several genes in our C. coli 76339 which were absent in other clade 3 strains, but present in clade 1 or 2 (Table 5). A high Blast score ratio was found for half of the capsule polysaccharide
(CPS) locus genes with C. coli clade 1a (ST-1150 CC) [72]. These genes were absent in the other $C$. coli clade 1 and 2 strains. In addition, several genes encoding methylaccepting chemotaxis signal transduction proteins were found; all of which were also present in C. coli clade 1a, but not always in clades $1 \mathrm{~b}, 1 \mathrm{c}$ and 2 . Finally an oxygeninsensitive $\mathrm{NAD}(\mathrm{P}) \mathrm{H}$ nitroreductase was commonly found among clades 1 and 2 and our C. coli 76339, but absent in other clade 3 strains. Thus, gene flow among C. coli clades is possible and probably depends on a number of factors facilitating homologous recombination, such as a shared ecological niche or transient co-colonization of the same host.

Table 5 Genes possibly acquired through gene flow by C. coli 76339

\begin{tabular}{|c|c|c|c|}
\hline Locus tag & RAST annotation & Present in & Missing in \\
\hline BN865_01630 & Methyl-accepting chemotaxis signal transduction protein & $\mathrm{C} 1 \mathrm{a} ; \mathrm{C} 1 \mathrm{~b}$ & $\mathrm{C} 1 \mathrm{C} ; \mathrm{C} 2$ \\
\hline BN865_02140 & Methyl-accepting chemotaxis signal transduction protein & $\mathrm{C} 1 \mathrm{a} ; \mathrm{C2}$ & $\mathrm{C} 1 \mathrm{~b} ; \mathrm{C} 1 \mathrm{c}$ \\
\hline BN865_02630c & Methyl-accepting chemotaxis signal transduction protein & Cla & $\mathrm{C} 1 \mathrm{~b} ; \mathrm{C} 1 \mathrm{c} ; \mathrm{C2}$ \\
\hline BN865_02680C & McrBC restriction endonuclease system, McrB subunit, putative & C2 & $\mathrm{Cla} ; \mathrm{C} 1 \mathrm{~b} ; \mathrm{Clc}$ \\
\hline BN865_03910 & Conserved hypothetical secreted protein & $\mathrm{C} 2$ & $\mathrm{Cla} ; \mathrm{C} 1 \mathrm{~b} ; \mathrm{Clc}$ \\
\hline BN865_04310C & FIG 00470070: hypothetical protein & Cla & $\mathrm{C} 1 \mathrm{~b} ; \mathrm{C} 1 \mathrm{c} ; \mathrm{C} 2$ \\
\hline BN865_05840c & Methyl-accepting chemotaxis signal transduction protein, fragment & Cla & $\mathrm{C} 1 \mathrm{~b} ; \mathrm{C} 1 \mathrm{c} ; \mathrm{C} 2$ \\
\hline BN865_05850c & Methyl-accepting chemotaxis signal transduction protein, fragment & Cla & $\mathrm{C} 1 \mathrm{~b} ; \mathrm{C} 1 \mathrm{c} ; \mathrm{C} 2$ \\
\hline BN865_06160 & Hypothetical protein & C1a; C2 & $\mathrm{C} 1 \mathrm{~b} ; \mathrm{C} 1 \mathrm{c}$ \\
\hline BN865_06170 & Hypothetical protein & $\mathrm{C} 1 \mathrm{a} ; \mathrm{C2}$ & $\mathrm{C} 1 \mathrm{~b} ; \mathrm{C} 1 \mathrm{c}$ \\
\hline BN865_06850c & Beta-1,3-glucosyltransferase & $\mathrm{Cla} ; \mathrm{C2}$ & $\mathrm{C} 1 \mathrm{~b} ; \mathrm{C} 1 \mathrm{c}$ \\
\hline BN865_07080 & Hypothetical protein & Cla & $\mathrm{C} 1 \mathrm{~b} ; \mathrm{C} 1 \mathrm{c} ; \mathrm{C} 2$ \\
\hline BN865_07090 & 2-dehydro-3-deoxyglucarate aldolase (EC 4.1.2.20) & Cla & $\mathrm{C} 1 \mathrm{~b} ; \mathrm{C} 1 \mathrm{c} ; \mathrm{C} 2$ \\
\hline BN865_07100 & D-3-phosphoglycerate dehydrogenase (EC 1.1.1.95) & Cla & $\mathrm{C} 1 \mathrm{~b} ; \mathrm{C} 1 \mathrm{c} ; \mathrm{C} 2$ \\
\hline BN865_07110 & NAD-dependent epimerase/dehydratase & Cla & $\mathrm{C} 1 \mathrm{~b} ; \mathrm{C} 1 \mathrm{c} ; \mathrm{C} 2$ \\
\hline BN865_07120 & Putative cyclase superfamily & Cla & $\mathrm{C} 1 \mathrm{~b} ; \mathrm{C} 1 \mathrm{c} ; \mathrm{C} 2$ \\
\hline BN865_07130 & Conserved hypothetical protein 22 & Cla & $\mathrm{C} 1 \mathrm{~b} ; \mathrm{C} 1 \mathrm{c} ; \mathrm{C} 2$ \\
\hline BN865_07140 & Hydrolase, haloacid dehalogenase-like family & Cla & $\mathrm{C} 1 \mathrm{~b} ; \mathrm{C} 1 \mathrm{c} ; \mathrm{C} 2$ \\
\hline BN865_07150 & $\begin{array}{l}\text { CMP-N-acetylneuraminate-beta-galactosamide- alpha-2, } \\
\text { 3-sialyltransferase (EC 2.4.99.-) }\end{array}$ & Cla & $\mathrm{C} 1 \mathrm{~b} ; \mathrm{C} 1 \mathrm{c} ; \mathrm{C} 2$ \\
\hline BN865_07160 & FIG 00470714: hypothetical protein & Cla & $\mathrm{C} 1 \mathrm{~b} ; \mathrm{C} 1 \mathrm{c} ; \mathrm{C} 2$ \\
\hline BN865_07180 & $\begin{array}{l}\text { Haloacid dehalogenase-like hydrolase domain/ } \\
\text { phosphoribulokinase domain protein }\end{array}$ & Cla & $\mathrm{C} 1 \mathrm{~b} ; \mathrm{C} 1 \mathrm{c} ; \mathrm{C} 2$ \\
\hline BN865_07190 & Capsular polysaccharide biosynthesis protein, putative & Cla & $\mathrm{C} 1 \mathrm{~b} ; \mathrm{C} 1 \mathrm{c} ; \mathrm{C} 2$ \\
\hline BN865_07200 & Capsular polysaccharide biosynthesis protein, putative & Cla & $\mathrm{C} 1 \mathrm{~b} ; \mathrm{C} 1 \mathrm{c} ; \mathrm{C} 2$ \\
\hline BN865_08140c & Methionyl-tRNA formyltransferase (EC 2.1.2.9) & Cla & $\mathrm{C} 1 \mathrm{~b} ; \mathrm{Clc} ; \mathrm{C} 2$ \\
\hline BN865_10680c & $\begin{array}{l}\text { Oxygen-insensitive NAD(P)H nitroreductase (EC 1.-.-.)/ } \\
\text { Dihydropteridine reductase (EC 1.5.1.34) }\end{array}$ & $\mathrm{Cla} ; \mathrm{C} 1 \mathrm{~b} ; \mathrm{C} 1 \mathrm{c} ; \mathrm{C} 2$ & - \\
\hline BN865_10830 & Hypothetical protein & $\mathrm{C} 2$ & $\mathrm{Cla} ; \mathrm{C} 1 \mathrm{~b} ; \mathrm{Clc}$ \\
\hline BN865_14240 & Possible sugar transferase & Cla & $\mathrm{C} 1 \mathrm{~b} ; \mathrm{C} 1 \mathrm{c} ; \mathrm{C} 2$ \\
\hline BN865_14270 & $\begin{array}{l}\text { Methyltransferase (EC 2.1.1.-), possibly involved in O-methyl } \\
\text { phosphoramidate capsule modification }\end{array}$ & $\mathrm{C} 1 \mathrm{a} ; \mathrm{C} 1 \mathrm{~b}$ & $\mathrm{C} 1 \mathrm{c} ; \mathrm{C} 2$ \\
\hline BN865_14740 & Family of unknown function (DUF450) family & Cla & $\mathrm{C} 1 \mathrm{~b} ; \mathrm{Clc} ; \mathrm{C} 2$ \\
\hline
\end{tabular}

The genes listed here were absent in other clade 3 strains, but present in C. coli clades 1 or 2 . 


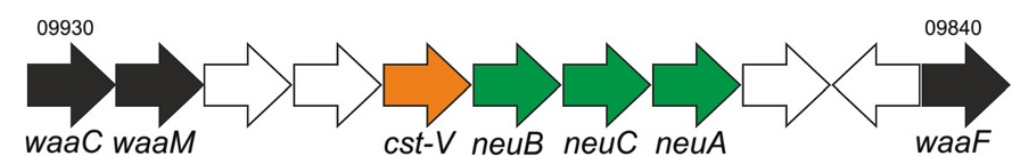

Figure 5 Lipooligosaccharide (LOS) locus C. coli strain 76339 located between waaC (BN865_09930) and waaF (BN865_09840).

Conserved genes are indicated using black arrows. Putative glycosyltransferases are shown in white, sialyltransferase cst- $V$ in orange and the sialic acid biosynthesis genes (neuBCA) in green.

\section{Evidence of LOS sialylation of C. coli 76339}

Using a BLAST score ratio cut off of 0.4 , a putative sialyltransferase (BN865_09900) was detected (Additional file 4: Table S2). This protein is located in the LOS locus upstream of three genes necessary for the biosynthesis and transfer of sialic acid (neuABC), resembling C. jejuni LOS locus classes A and B (Figure 5) [73] but not other C. coli LOS locus classes described by Richards and colleagues [72]. The presence of these particular genes in the LOS locus suggests that strain 76339 may express sialylated LOS structures [74]. HPAEC-PAD analysis of the purified LOS obtained from C. coli 76339 revealed the presence of sialic acid, supporting the genomic results. This finding is important because it would imply that certain $C$. coli could also have bacterial factors considered important in the pathogenesis of Guillain-Barré syndrome $[2,3]$. It remains unknown, however, onto which substrate the sialic acid is transferred and thus whether or not this structure would mimic human gangliosides, and further studies are needed to deduce the structure.

No evidence has been found of the presence of the $n e u A B C$ gene cluster in the LOS locus of any of the 42 C. coli strains analyzed in a previous study [72], although it was evident in the CPS locus classes VII and VIII [72].
However, the authors found the presence of a putative sialyltransferase (named 1501) in two LOS classes of $C$. coli (class B and C). In our MCL cluster analysis we found that the putative $C$. coli 76339 sialyltransferase BN865_09900 belongs to GO-CCO2667 which includes several other sequences from both $C$. coli clade 1 and 3 . All the sequences of GO-CCO2667, showed a significant homology to those belonging to the CAZy glycosyltransferase family GT42, supporting the idea that all encode putative sialyltransferases [32]. Further analysis revealed that the clade 1 GO-CCO2667 sequences corresponded to sialyltransferase 1501 identified by Richards et al. [72]. Additionally, C. coli 76339 possesses a second sialyltransferase (BN865_06990), which was found to be located in the CPS locus of the strain and to have an ortholog in other clade 3 strains. This protein gave no significant BLASTP hits with other C. coli sequences (BSR cut off 0.4 ), but it showed $67 \%$ identity with C. jejuni ATCC 43456 Cst-I. To elucidate the phylogenetic relationship among Campylobacter sialyltransferases we inferred the phylogeny of GT42 sequences by applying Bayesian methodology (Figure 6). The LOS-associated C. coli sialyltranferases were shown to be monophyletic and distantly related to $C$. jejuni sialyltransferases. We propose

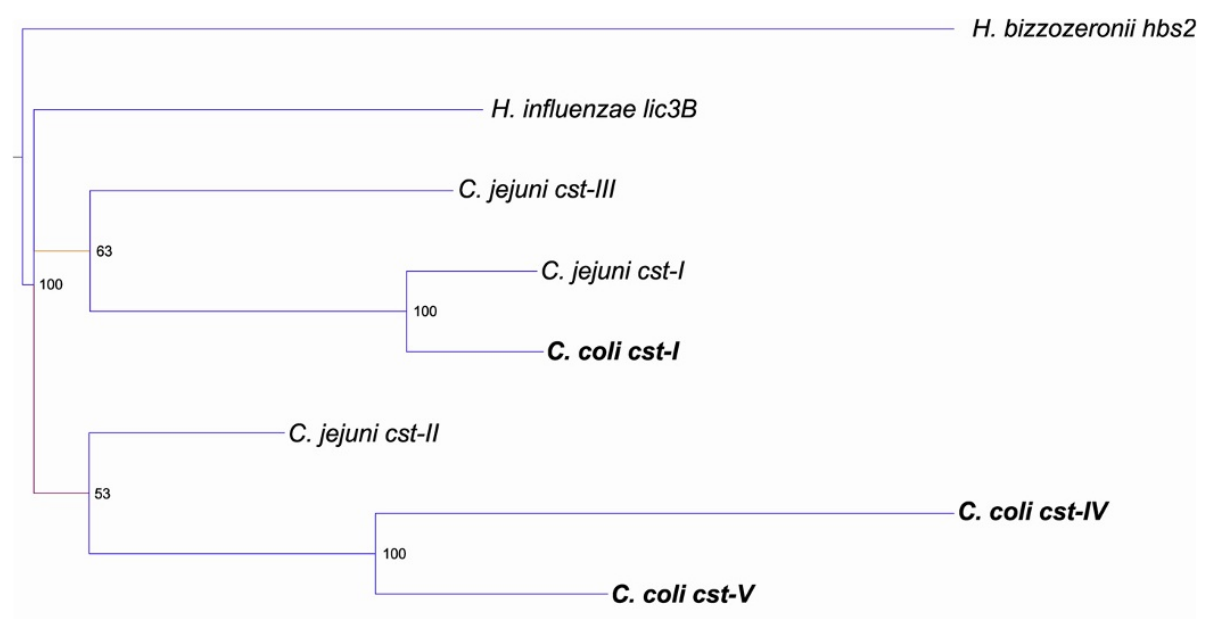

Figure 6 Bayesian phylogeny of GT42 sialyltransferases indicating relatedness of $C$. jejuni and C. coli sialyltransferases. C. coli Cst-I is found in the capsule (CPS) locus of C. coli clade 3 strains and is an ortholog of C. jejuni cst-I. C. coli cst-IV is found in the lipooligosaccharide (LOS) locus of $C$. coli clade 1 strains and $C$. coli cst-V is found in the LOS locus of C. coli clade 3 strains. 
to name these genes Cst-IV (clade 1) and Cst-V (clade 3). The distant relationship observed between LOS-associated C. coli and C. jejuni sialyltransferases could indicate evolution of different substrate specificity, which has been previously observed among Helicobacter sialyltransferases [52]. As a consequence, these bacteria may express different sialylated structures on their LOS. On the contrary, the $C$. coli clade 3 sialyltransferases located within the capsule locus clustered tightly together with C. jejuni Cst-I, which supports the notion of interspecies HGT and the potential of sharing similar sialylated glycan structures on the surface.

\section{Conclusions}

From a phylogenetic point of view we found $C$. coli clades 2 and 3 to be monophyletic, rather than paraphyletic [14], implying common ancestry, in which both gene extinction and HGT could play a plausible role in the separation of two distinct clades. Furthermore, unintrogressed C. coli clade 3 strains show potential for an extensive respiratory metabolism; possibly reflecting their wide host range and adaptability to novel niches. Finally, we propose a new insight into the evolution of the accessory genome of both C. coli and C. jejuni, which should be exploited further with other dispensable genes.

\section{Availability of supporting data}

The genome of C. coli 76339 was deposited in EMBL under accession number HG326877. Trees were submitted to Treebase and are available for download at http:// purl.org/phylo/treebase/phylows/study/TB2:S15193. The Ccoli-DB and the groups of orthologs are available at the University of Helsinki for download at http://www. mv.helsinki.fi/mirossi/C.coli-DB/ or upon request to the author.

\section{Additional files}

Additional file 1: Table S1. List of C. coli and C. jejuni genomes used in this study.

Additional file 2: Figure S1. Bayesian $\varepsilon$-proteobacteria species tree based on the small ribosomal unit.

Additional file 3: Figure S2. Maximum likelihood tree rooted with C. coli 76339, representing the evolution of C. jejuni. The ML tree is based on whole genome sequence alignment, with a node support of $>90 \%$. Presence or absence of the ggt gene is indicated. C. jejuni clonal complexes are separated into seven clades.

Additional file 4: Table S2. CDSs of C. coli 76339 with no significant BLASTP result versus other $C$. coli proteins. A BLAST score ratio (BSR) cut-off 0.4 was used.

\section{Competing interests}

The authors declare that they have no competing interests.

\section{Authors' contributions}

CPAdH participated in the genome assembly and analysis and in drafting the manuscript. AC carried out experimental work. TS performed the genome assembly and annotation. JR was involved in characterization of the LOS locus. EKHS has carried out the phenotypic characterization of the LOS structure. MLH conceived the idea. MR has carried out the phylogenetic analysis, the comparative genomic and in drafting the manuscript. All authors have been involved in drafting of the manuscript. All authors read and approve the manuscript

\section{Acknowledgments}

We are grateful to Dr. Sam Sheppard for providing the genomic data on C. coli clade 2 and 3 strains. We would also like to thank Urszula Hirvi for technical assistance. This work was supported by funding from the Academy of Finland through the Centre of Excellence on Microbiological Food Safety no. 141140.

\section{Author details}

'Department of Food Hygiene and Environmental Health, Helsinki University, Helsinki, Finland. ²Division of Chemistry, IFM, Linköping University, Linköping, Sweden.

Received: 27 August 2013 Accepted: 5 February 2014 Published: 13 February 2014

\section{References}

1. European Food Safety Authority (EFSA), European Centre for Disease Prevention and Contro: The European union summary report on trends and sources of Zoonoses, Zoonotic agents and food-borne outbreaks in 2011. EFSA J 2013, 11((4):3129):74-85.

2. Bersudsky M, Rosenberg P, Rudensky B, Wirguin I: Lipopolysaccharides of a Campylobacter coli isolate from a patient with Guillain-Barre syndrome display ganglioside mimicry. Neuromuscul Disord 2000, 10(3):182-186.

3. van Belkum A, Jacobs B, van Beek E, Louwen R, van Rijs W, Debruyne L, Gilbert M, Li J, Jansz A, Megraud F, Endtz H: Can Campylobacter coli induce Guillain-Barre syndrome? Eur J Clin Microbiol Infect Dis 2009, 28(5):557-560

4. Gillespie IA, O'Brien SJ, Frost JA, Adak GK, Horby P, Swan AV, Painter MJ, Neal KR, Campylobacter Sentinel Surveillance Scheme Collaborators: A case-case comparison of Campylobacter coli and Campylobacter jejuni infection: a tool for generating hypotheses. Emerg Infect Dis 2002, 8(9):937-942.

5. Tam CC, O'Brien SJ, Adak GK, Meakins SM, Frost JA: Campylobacter coli-an important foodborne pathogen. J Infect 2003, 47(1):28-32.

6. Doorduyn Y, Van Den Brandhof WE, Van Duynhoven YT, Breukink BJ, Wagenaar JA, Van Pelt W: Risk factors for indigenous Campylobacter jejuni and Campylobacter coli infections in The Netherlands: a case-control study. Epidemiol Infect 2010, 138(10):1391-1404.

7. Roux F, Sproston E, Rotariu O, Macrae M, Sheppard SK, Bessell P, Smith-Palmer A, Cowden J, Maiden MC, Forbes KJ, Strachan NJ: Elucidating the aetiology of human campylobacter coli infections. PLoS One 2013, 8(5):e64504.

8. Neimann J, Engberg J, Molbak K, Wegener HC: A case-control study of risk factors for sporadic campylobacter infections in Denmark. Epidemiol Infect 2003, 130(3):353-366.

9. Kärenlampi R, Rautelin H, Schönberg-Norio D, Paulin L, Hänninen ML: Longitudinal study of Finnish Campylobacter jejuni and C. coli isolates from humans, using multilocus sequence typing, including comparison with epidemiological data and isolates from poultry and cattle. Appl Environ Microbiol 2007, 73(1):148-155.

10. Olson KE, Ethelberg S, van Pelt W, Tauxe RV: Epidemiology of Campylobacter jejuni Infections in Industrialized Nations. In Campylobacter. Thirdth edition. Edited by Nachamkin I, Szymanski CM, Blaser MJ. Washington, DC, USA: ASM Press; 2008:163-189.

11. Bessede E, Lehours P, Labadi L, Bakiri S, Megraud F: Comparison of Characteristics of Patients Infected by Campylobacter jejuni, Campylobacter coli, and Campylobacter fetus. J Clin Microbiol 2014, 52(1):328-330.

12. Wright S, Wilson S, Miller WG, Mandrell RE, Siletzky RM, Kathariou S: Differences in methylation at GATC sites in genomic DNA of Campylobacter coli from turkeys and swine. Appl Environ Microbiol 2010, 76(21):7314-7317. 
13. Sheppard SK, McCarthy ND, Falush D, Maiden MC: Convergence of Campylobacter species: implications for bacterial evolution. Science 2008 320(5873):237-239.

14. Sheppard SK, Didelot X, Jolley KA, Darling AE, Pascoe B, Meric G, Kelly DJ, Cody A, Colles FM, Strachan NJ, Ogden ID, Forbes K, French NP, Carter P, Miller WG, McCarthy ND, Owen R, Litrup E, Egholm M, Affourtit JP, Bentley SD, Parkhill J, Maiden MC, Falush D: Progressive genome-wide introgression in agricultural Campylobacter coli. Mol Ecol 2013, 22(4):1051-1064.

15. Jolley KA, Maiden MC: BIGSdb: scalable analysis of bacterial genome variation at the population level. BMC Bioinforma 2010, 11:595.

16. Rossi M, Bolz C, Revez J, Javed S, El-Najjar N, Anderl F, Hyytiäinen H, Vuorela P, Gerhard M, Hänninen ML: Evidence for conserved function of gammaglutamyltranspeptidase in Helicobacter genus. PLoS One 2012, 7(2):e30543.

17. Hofreuter D, Novik V, Galan JE: Metabolic diversity in Campylobacter jejuni enhances specific tissue colonization. Cell Host Microbe 2008, 4(5):425-433.

18. de Haan CP, Llarena AK, Revez J, Hänninen ML: Association of Campylobacter jejuni metabolic traits with multilocus sequence types. Appl Environ Microbiol 2012, 78(16):5550-5554.

19. Zautner AE, Herrmann S, Corso J, Tareen AM, Alter T, Gross U: Epidemiological association of different Campylobacter jejuni groups with metabolism-associated genetic markers. Appl Environ Microbiol 2011, 77(7):2359-2365

20. Feodoroff $B$, Ellström $P$, Hyytiäinen $H$, Sarna $S$, Hänninen $M L$, Rautelin $H$ : Campylobacter jejuni isolates in Finnish patients differ according to the origin of infection. Gut Pathog 2010, 2(1):22

21. Denis M, Soumet C, Rivoal K, Ermel G, Blivet D, Salvat G, Colin P. Development of a m-PCR assay for simultaneous identification of Campylobacter jejuni and C. coli. Lett Appl Microbiol 1999, 29(6):406-410.

22. Dingle KE, Colles FM, Wareing DR, Ure R, Fox AJ, Bolton FE, Bootsma HJ, Willems RJ, Urwin R, Maiden MC: Multilocus sequence typing system for Campylobacter jejuni. J Clin Microbiol 2001, 39(1):14-23.

23. Miller WG, On SL, Wang G, Fontanoz S, Lastovica AJ, Mandrell RE: Extended multilocus sequence typing system for Campylobacter coli, C. lari, C. upsaliensis, and C. helveticus. J Clin Microbiol 2005, 43(5):2315-2329.

24. Korczak BM, Zurfluh M, Emler S, Kuhn-Oertli J, Kuhnert P: Multiplex strategy for multilocus sequence typing, fla typing, and genetic determination of antimicrobial resistance of Campylobacter jejuni and Campylobacter coli isolates collected in Switzerland. J Clin Microbiol 2009, 47(7):1996-2007.

25. de Haan CP, Kivistö R, Hakkinen M, Rautelin H, Hänninen ML: Decreasing trend of overlapping multilocus sequence types between human and chicken Campylobacter jejuni isolates over a decade in Finland. Appl Environ Microbiol 2010, 76(15):5228-5236.

26. Chevreux B, Wetter T, Suhai S: Genome sequence assembly using trace signals and additional sequence information. Comput Sci and Biol: Proc Ger Conf on Bioinformatics (GCB) 1999, 99:45-56.

27. Warren RL, Sutton GG, Jones SJ, Holt RA: Assembling millions of short DNA sequences using SSAKE. Bioinformatics 2007, 23(4):500-501.

28. Staden R, Beal KF, Bonfield JK: The Staden package, 1998. Methods Mol Biol 2000, 132:115-130

29. Aziz RK, Bartels D, Best AA, DeJongh M, Disz T, Edwards RA, Formsma K, Gerdes S, Glass EM, Kubal M, Meyer F, Olsen GJ, Olson R, Osterman AL, Overbeek RA, McNeil LK, Paarmann D, Paczian T, Parrello B, Pusch GD, Reich C, Stevens R, Vassieva O, Vonstein V, Wilke A, Zagnitko O: The RAST Server: rapid annotations using subsystems technology. BMC Genomics 2008, 9. doi:10.1186/1471-2164-9-75.

30. Rutherford K, Parkhill J, Crook J, Horsnell T, Rice P, Rajandream MA, Barrell B: Artemis: sequence visualization and annotation. Bioinformatics 2000, 16(10):944-945.

31. Mulder NJ, Apweiler R: The InterPro database and tools for protein domain analysis. Curr Protoc Bioinformatics 2008. doi:10.1002/0471250953.bi0207s21.

32. Cantarel BL, Coutinho PM, Rancurel C, Bernard T, Lombard V, Henrissat B: The Carbohydrate-Active EnZymes database (CAZy): an expert resource for Glycogenomics. Nucleic Acids Res 2009, 37(Database issue):D233-D238.

33. Angiuoli SV, Salzberg SL: Mugsy: fast multiple alignment of closely related whole genomes. Bioinformatics 2011, 27(3):334-342.

34. Fricke WF, Mammel MK, McDermott PF, Tartera C, White DG, Leclerc JE, Ravel J, Cebula TA: Comparative genomics of 28 Salmonella enterica isolates: evidence for CRISPR-mediated adaptive sublineage evolution. J Bacteriol 2011, 193(14):3556-3568.

35. Giardine B, Riemer C, Hardison RC, Burhans R, Elnitski L, Shah P, Zhang Y, Blankenberg D, Albert I, Taylor J, Miller W, Kent WJ, Nekrutenko A: Galaxy: a platform for interactive large-scale genome analysis. Genome Res 2005, 15(10):1451-1455.

36. Blankenberg D, Von Kuster G, Coraor N, Ananda G, Lazarus R, Mangan M, Nekrutenko A, Taylor J: Galaxy: a web-based genome analysis tool for experimentalists. Curr Protoc Mol Biol 2010: doi:10.1002/0471142727. mb1910s89.

37. Goecks J, Nekrutenko A, Taylor J, Galaxy Team: Galaxy: a comprehensive approach for supporting accessible, reproducible, and transparent computational research in the life sciences. Genome Biol 2010, 11(8):R86-2010-11-8-r86. Epub 2010 Aug 25.

38. Castresana J: Selection of conserved blocks from multiple alignments for their use in phylogenetic analysis. Mol Biol Evol 2000, 17(4):540-552.

39. Liu K, Linder CR, Warnow T: RAxML and FastTree: comparing two methods for large-scale maximum likelihood phylogeny estimation. PLOS One 2011, 6(11):e27731.

40. Price MN, Dehal PS, Arkin AP: FastTree 2-approximately maximumlikelihood trees for large alignments. PLoS One 2010, 5(3):e9490.

41. Darriba D, Taboada GL, Doallo R, Posada D: jModelTest 2: more models, new heuristics and parallel computing. Nat Methods 2012, 9(8):772

42. Katoh K, Standley DM: MAFFT multiple sequence alignment software version 7: improvements in performance and usability. Mol Biol Evol 2013, 30(4):772-780

43. Abascal F, Zardoya R, Telford MJ: TranslatorX: multiple alignment of nucleotide sequences guided by amino acid translations. Nucleic Acids Res 2010, 38(Web Server issue):W7-W13.

44. Hogan M, Siegmund D: Large deviations for the maxima of some random fields. Adv Appl Math 1986, 7(1):2-22.

45. Boni MF, Posada D, Feldman MW: An exact nonparametric method for inferring mosaic structure in sequence triplets. Genetics 2007, 176(2):1035-1047.

46. Bruen TC, Philippe $H$, Bryant D: A simple and robust statistical test for detecting the presence of recombination. Genetics 2006, 172(4):2665-2681.

47. Smith JM: Analyzing the mosaic structure of genes. J Mol Evol 1992, 34(2):126-129.

48. Jakobsen IB, Easteal S: A program for calculating and displaying compatibility matrices as an aid in determining reticulate evolution in molecular sequences. Comput Appl Biosci 1996, 12(4):291-295.

49. Bruen T, Bruen T: PhiPack: PHI test and other tests of recombination. Montreal, Quebec: McGill University; 2005

50. Guindon S, Dufayard JF, Lefort V, Anisimova M, Hordijk W, Gascuel O: New algorithms and methods to estimate maximum-likelihood phylogenies: assessing the performance of PhyML 3.0. Syst Biol 2010, 59(3):307-321.

51. Felsenstein J: PHYLIP - Phylogeny Inference Package (version 3.2). Cladistics 1989, 5:164-166

52. Kondadi PK, Rossi M, Twelkmeyer B, Schur MJ, Li J, Schott T, Paulin L, Auvinen P, Hänninen ML, Schweda EK, Wakarchuk W: Identification and characterization of a lipopolysaccharide alpha,2,3-sialyltransferase from the human pathogen Helicobacter bizzozeronii. J Bacteriol 2012 194(10):2540-2550

53. Cole JR, Wang Q, Cardenas E, Fish J, Chai B, Farris RJ, Kulam-Syed-Mohideen AS, McGarrell DM, Marsh T, Garrity GM, Tiedje JM: The ribosomal database project: improved alignments and new tools for rRNA analysis. Nucleic Acids Res 2009, 37(Database issue):D141-D145.

54. Ronquist F, Teslenko M, van der Mark P, Ayres DL, Darling A, Hohna S, Larget B, Liu L, Suchard MA, Huelsenbeck JP: MrBayes 3.2: efficient Bayesian phylogenetic inference and model choice across a large model space. Syst Biol 2012, 61(3):539-542.

55. Huson DH, Bryant D: Application of phylogenetic networks in evolutionary studies. Mol Biol Evol 2006, 23(2):254-267.

56. Li L, Stoeckert CJ Jr, Roos DS: OrthoMCL: identification of ortholog groups for eukaryotic genomes. Genome Res 2003, 13(9):2178-2189.

57. Rasko DA, Myers GS, Ravel J: Visualization of comparative genomic analyses by BLAST score ratio. BMC Bioinforma 2005, 6(1):2

58. de Haan CP, Lampén K, Corander J, Hänninen ML: Multilocus sequence types of environmental Campylobacter jejuni isolates and their similarities to those of human, poultry and bovine $C$. jejuni isolates. Zoonoses Public Health 2013, 60(2):125-133.

59. Fouts DE, Mongodin EF, Mandrell RE, Miller WG, Rasko DA, Ravel J, Brinkac LM, DeBoy RT, Parker CT, Daugherty SC, Dodson RJ, Durkin AS, Madupu R, Sullivan SA, Shetty JU, Ayodeji MA, Shvartsbeyn A, Schatz MC, Badger JH, Fraser CM, Nelson KE: Major structural differences and novel potential 
virulence mechanisms from the genomes of multiple Campylobacter species. PLoS Biol 2005, 3(1):e15.

60. Lefébure T, Bitar PD, Suzuki H, Stanhope MJ: Evolutionary dynamics of complete Campylobacter pan-genomes and the bacterial species concept. Genome Biol Evol 2010, 2:646-655.

61. Lefébure T, Stanhope MJ: Pervasive, genome-wide positive selection leading to functional divergence in the bacterial genus Campylobacter. Genome Res 2009, 19(7):1224-1232.

62. Rawlings N, Barrett A: Evolutionary families of peptidases. Biochem J 1993, 15(290):205-218.

63. Hofreuter D, Tsai J, Watson RO, Novik V, Altman B, Benitez M, Clark C, Perbost C, Jarvie T, Du L, Galan JE: Unique features of a highly pathogenic Campylobacter jejuni strain. Infect Immun 2006, 74(8):4694-4707.

64. van Vliet AH, Ketley JM, Park SF, Penn CW: The role of iron in Campylobacter gene regulation, metabolism and oxidative stress defense. FEMS Microbiol Rev 2002, 26(2):173-186.

65. Holmes K, Mulholland F, Pearson BM, Pin C, McNicholl-Kennedy J, Ketley JM, Wells JM: Campylobacter jejuni gene expression in response to iron limitation and the role of Fur. Microbiology 2005, 151(Pt 1):243-257.

66. Miller $\mathrm{CE}$, Williams $\mathrm{PH}$, Ketley JM: Pumping iron: mechanisms for iron uptake by Campylobacter. Microbiology 2009, 155(Pt 10):3157-3165.

67. Stintzi A, van Vliet A, Ketley J: Iron Metabolism, Transport, and Regulation. In Campylobacter. 3rd edition. Edited by Nachamkin I, Szymanski C, Blaser M. Washington DC: ASM Press; 2008

68. Barnes IH, Bagnall MC, Browning DD, Thompson SA, Manning G, Newell DG: Gamma-glutamyl transpeptidase has a role in the persistent colonization of the avian gut by Campylobacter jejuni. Microb Pathog 2007, 43(5-6):198-207.

69. Sheppard SK, Colles FM, McCarthy ND, Strachan NJ, Ogden ID, Forbes KJ, Dallas JF, Maiden MC: Niche segregation and genetic structure of Campylobacter jejuni populations from wild and agricultural host species. Mol Ecol 2011, 20(16):3484-3490.

70. Gardner SP, Olson JW: 2 Barriers to Horizontal Gene Transfer in Campylobacter jejuni. Adv Appl Microbiol 2012, 79:19.

71. Dugar G, Herbig A, Forstner KU, Heidrich N, Reinhardt R, Nieselt K, Sharma CM: High-resolution transcriptome maps reveal strain-specific regulatory features of multiple campylobacter jejuni isolates. PLoS Genet 2013, 9(5):e1003495.

72. Richards VP, Lefébure T, Pavinski Bitar PD, Stanhope MJ: Comparative characterization of the virulence gene clusters (lipooligosaccharide [LOS] and capsular polysaccharide [CPS]) for Campylobacter coli, Campylobacter jejuni subsp. jejuni and related Campylobacter species. Infect Genet Evol 2013, 14:200-213.

73. Parker CT, Gilbert M, Yuki N, Endtz HP, Mandrell RE: Characterization of lipooligosaccharide-biosynthetic loci of Campylobacter jejuni reveals new lipooligosaccharide classes: evidence of mosaic organizations. J Bacteriol 2008, 190(16):5681-5689.

74. Godschalk PC, Heikema AP, Gilbert M, Komagamine T, Ang CW, Glerum J, Brochu D, Li J, Yuki N, Jacobs BC, van Belkum A, Endtz HP: The crucial role of Campylobacter jejuni genes in anti-ganglioside antibody induction in Guillain-Barre syndrome. J Clin Invest 2004, 114(11):1659-1665.

\section{Submit your next manuscript to BioMed Central and take full advantage of:}

- Convenient online submission

- Thorough peer review

- No space constraints or color figure charges

- Immediate publication on acceptance

- Inclusion in PubMed, CAS, Scopus and Google Scholar

- Research which is freely available for redistribution 